\title{
COLOUR POLYMORPHISM IN THE LAND ISOPOD ARMADILLIDIUM NASATUM*
}

\author{
S. LAURA ADAMKEWICZ $\dagger$ \\ Department of Biology, University of Virginia
}

Received 7.vi.68

\section{INTRODUGTION}

Armadillidium nasatum Budde-Lund is one of the commonest oniscoid isopods in the south-eastern United States (Schultz, 1961). In Albemarle County, Virginia, and probably throughout its range, the species is polymorphic for body colour. The Oniscoidea as a whole are quite variable in colour and pattern (Vandel, 1960, 1962), and several workers have studied the genetics of individual loci (for references see Vandel, 1945, 1962). Only two have dealt with the frequency of genes in populations. Howard (1940, 1953, 1962) has investigated the genetics of Armadillidium vulgare with some attention to populations. De Lattin $(1939,1951,1954)$ has studied the genetics of albinism and marbling in many species and has determined gene frequencies in some of them. However, neither study has seriously attempted to discover the causes for the polymorphisms. An extensive literature is available on the taxonomy (Vandel, 1960, 1962), physiology (Edney, 1954), and ecology (Hatchett, 1947; Brereton, 1957; Paris, 1962, 1963; Warburg, 1965) of land isopods. These works provide all the necessary background for investigations of population genetics in this large and widespread group of animals. Therefore, it seems important to apply to $A$. nasatum the techniques of ecological genetics so successfully used for other animals (Fisher and Ford, 1947; Cain and Sheppard, 1954; Dowdeswell, 1961).

\section{MEthods}

\section{(a) Collections}

All of the isopods used in this study were collected from natural populations in Albemarle County, Virginia, from September 1964 to May 1968. The study area is a rural one of rolling hills with pasture and mixed hardwood forests. The climate is temperate with about three inches of rain each month. In Virginia, $A$. nasatum inhabits the partially shaded areas around buildings, usually with lawn grasses and shade trees. It is rare in forests and open grasslands.

Most of the collections were taken from aggregations of isopods beneath a piece of cover such as a log or stone. After an object was raised, the animals clinging to it were brushed into a pan and the animals in the soil were scooped up with a spoon. Since the procedure did not rely on a visual search for individuals, a colour bias in the sampling was unlikely. The animals were taken to the laboratory and kept at $7^{\circ} \mathrm{C}$. until scored. Holding at this low temperature reduced mortality considerably.

* Supported in part by an NDEA Title IV fellowship and in part by a Virginia Mason Davidge fellowship; part of a dissertation presented to the University of Virginia.

$\dagger$ Present address: Department of Zoology, Syracuse University. 


\section{(b) Scoring}

Each animal was examined under a dissecting microscope and scored for colour, sex and body length. The length from the tip of the epistome to the tip of the telson is a reliable measure of the isopod's age. This distance was measured to the nearest millimetre by positioning the animal over a grid. No reference standard for colour was needed because the red class was quite distinct, but reliability was checked by scoring some collections twice. The two scores generally agreed \pm 1 per cent. Sex was determined by the shape of the pleopods, which are rectangular in females and pointed in males. Only individuals $5 \mathrm{~mm}$. or longer were sexed. Below that size, the male's pleopods are not completely differentiated.

\section{(c) Culture methods}

Adults were kept in 6-in. Petri dishes with discs of moist Whatman No. 1 filter paper on the bottom and a folded piece of the same paper in the centre. Breeding stock and young were kept in 4-oz. glass jars with dry paper on the bottom. The tops were fitted with air holes and shell vials that were filled with water and stoppered with cotton. This arrangement kept the humidity high while avoiding free water. All cultures were fed blackboard chalk and sli ces of potato and carrot. Changes in diet did not affect the body colours.

\section{Phenotypes}

Observation of individuals from natural populations and of young reared in the laboratory shows that body colour in $A$. nasatum varies both quantitatively and qualitatively. The quantitative variations are a normal result of the life-cycle; but the qualitative variations constitute, as this study will show, a genetic polymorphism. Three colour forms occur in natural populations. One is reddish-brown, here called red, very similar to human " red" hair. The colour referred to as "dark" can be either black or chocolate brown. In all forms the eyes and a region around the mouth are black. Whether black and brown are genetically different cannot be determined at present because the two cannot be distinguished reliably. For the purposes of this study, red is contrasted to dark. Intermediate phenotypes do occur, but not so frequently as to make scoring difficult.

All young are born colourless with red eyes and begin to show the body colour at about 2 months of age. Adults are darker than young, and males are more heavily pigmented than females. In adult males, the vas deferens has the same pigment as the epidermis and appears as a spot of colour through the ventral cuticle of the seventh thoracic segment. Almost all dark young, and some adults, have an area of pale red on the rim of the first thoracic segment. Occasionally, all the segments have red on the rims, giving a lightly pigmented animal an intermediate appearance. Three true mosaics were collected, two females and a male, with the normal dark pigment on half the seventh thoracic segment replaced by red. One of the females produced a segregating brood (Spot in table 1), indicating that she was heterozygous. Whatever the basis of the mosaicism, the animals demonstrate that both red and dark pigments can exist in the same body, unlike some mutant eye colours in insects.

Previous studies have shown that the epidermal pigments of Asellus 
(Needham and Brunet, 1957) and Idothea (Lee, 1966) are ommochromes. However, both species are aquatic, and the pigments do not vary. Experiments with $A$. nasatum show that the pigments of this species are also ommochromes. Extractions were made either from single isopods or from batches carefully matched for colour. The animals were always decapitated to eliminate the eye pigments. The extraction procedure of Needham and Brunet was followed. First the bodies were ground in acetone and the colourless supernatant discarded. Next the tissue was ground in acid methanol ( 1 per cent. by volume $\mathrm{HCl}$ ). The debris was centrifuged down and the supernatant used with no further purification. Extracts from black

TABLE 1

Matings of wild-caught virgins

$\begin{array}{cccccc}\text { Female } & \text { Male } & \begin{array}{c}\text { Young } \\ \text { born }\end{array} & \begin{array}{c}\text { Young scored } \\ \text { Dark }: \text { Red }=\text { Total }\end{array} & \begin{array}{c}\text { Expected } \\ \text { ratio }\end{array} & \begin{array}{c}\text { Significant } \\ \text { at } 5 \% \text { level }\end{array} \\ \text { RW1 } & \text { RM1 } & 19 & 0: 15=15 & 0: 1 & \text { * } \\ \text { RW2 } & \text { RM1 } & 10 & 0: 8=8 & 0: 1 & - \\ \text { RW9 } & \text { RM1 } & 8 & 0: 3=3 & 0: 1 & * \\ \text { RW3 } & \text { RM2 } & 19 & 0: 15=15 & 0: 1 & * \\ \text { RW4 } & \text { RM3 } & 12 & 0: 11=11 & 0: 1 & - \\ \text { RW5 } & \text { RM3 } & 8 & 0: 4=4 & 0: 1 & - \\ \text { RW6 } & \text { RS1 } & 16 & 0: 9=9 & 0: 1 & - \\ \text { RW8 } & \text { RS2 } & 11 & 0: 5=5 & 0: 1 & - \\ \text { IW1 } & \text { DS1 } & 14 & 4: 4=8 & - & - \\ \text { IW2 } & \text { DS1 } & 12 & 7: 0=7 & - & - \\ \text { IW3 } & \text { DS1 } & 11 & 8: 3=11 & - & - \\ \text { IW4 } & \text { DS2 } & 13 & 4: 2=6 & - \\ \text { IW5 } & \text { DS2 } & 20 & 7: 3=10 & 3: 1 & - \\ \text { DW1 } & \text { DS3 } & 17 & 10: 3=13 & 3: 1 & - \\ \text { DW2 } & \text { DS3 } & 10 & 1: 1=2 & 3: 1 & - \\ \text { DW3 } & \text { DS3 } & 19 & 7: 4=11 & -\end{array}$

The letters $\mathbf{R}, \mathbf{I}$, and D refer to the colour of the animals, red, intermediate, or dark. $\mathrm{W}$ signifies wild-caught virgin. $\mathbf{M}$ and $\mathrm{S}$ refer to the population from which the animals were taken, Murray or Searls. The female "Spot" was a non-virgin mosaic.

animals were wine red, from red animals were yellow, and from brown animals were orange. Scanning with a double-beam spectrophotometer produced the absorption spectra shown in fig. 1. A mixture of extracts from red and black was the same colour as an extract from brown and gave an identical spectrum.

The pigments had the chemical properties of ommochromes (Needham and Brunet, 1957; Lee, 1966). They were extracted by acid methanol, formic acid, aqueous $\mathrm{HCl}$, and aqueous urea ( 10 per cent. w/v) but not by water, methanol or acetone. They showed a reversible colour change upon oxidation. After addition of sodium nitrite, all extracts turned brilliant yellow, a different shade from fresh extracts of red animals. When sodium borohydride was added, the oxidised solutions became pale pink, but the original colours were not restored.

To determine whether the solutions contained more than one pigment, ascending chromatograms were made on Whatman No. 1 paper using concentrated formic acid (fig. 2). When $0.05 \mathrm{ml}$. of methanol extract was applied to the paper, the colour was clearly visible. The spot with $R_{f}=0 \cdot 8$ was yellow and fluoresced in ultraviolet light. The spot with $R_{f}=0.6$ was 
pink and not fluorescent. After the yellow spots from red and black animals were eluted with acid methanol, they gave spectra identical to each other and to fresh extracts from red animals. Extracts from black individuals of $A$. vulgare gave chromatograms indistinguishable from those of black $A$. nasatum, suggesting that the pigment systems are the same. No red A. vulgare were available.

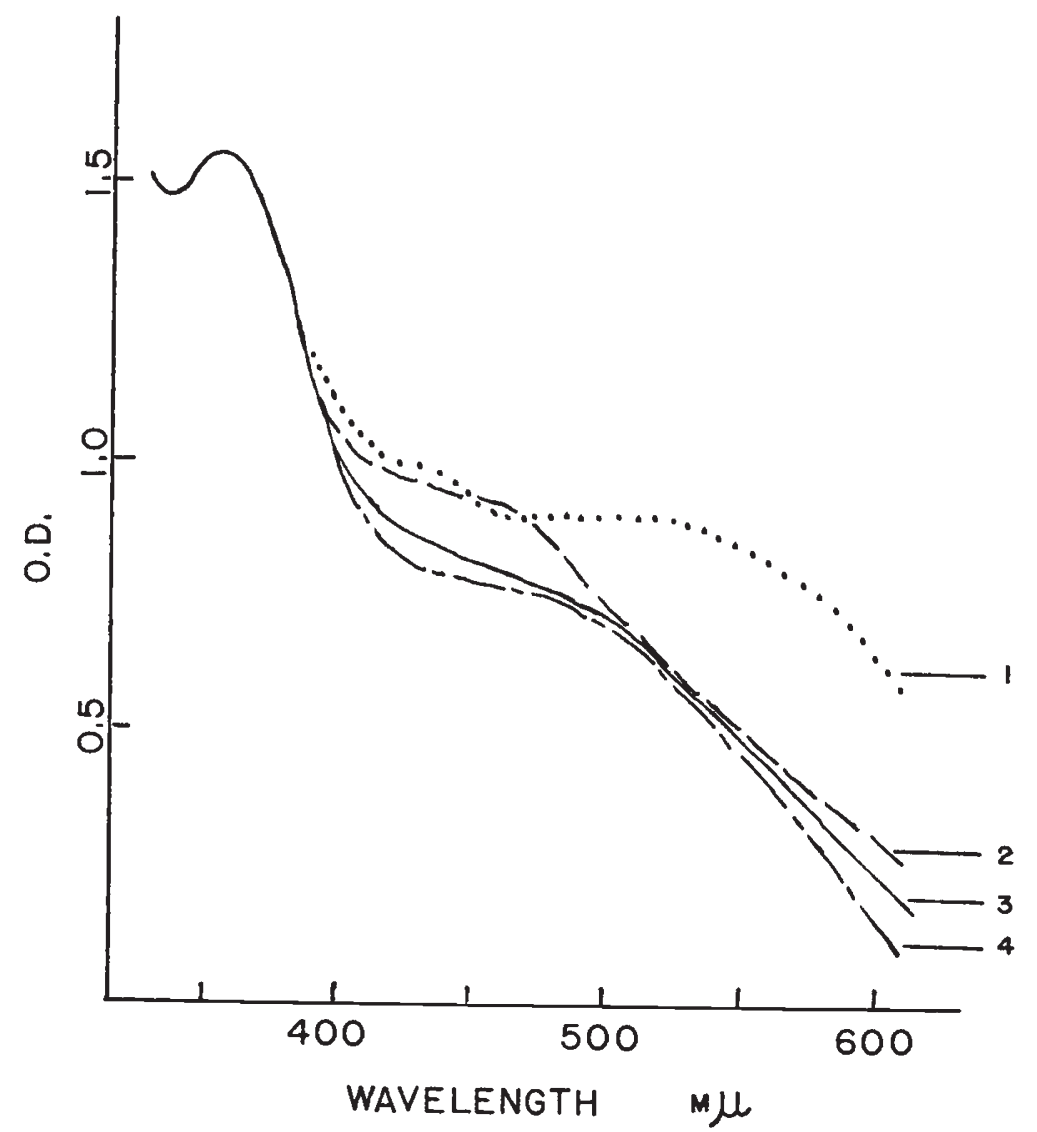

Fig. 1.-Absorption spectra of acid methanol extracts from isopods with (1) black, (2) red, and (3) brown phenotypes together with the spectrum (4) of a mixture of red and black; all normalised at $360 \mathrm{~m} \mu$.

Clearly, red is the absence of a dark pigment, and the observation that dark animals occasionally have some red on their bodies is consistent with the hypothesis that they normally have two pigments with the darker masking the lighter. Black and brown appear to differ only quantitatively. Needham and Brunet (1957) mention a wine-coloured pigment that they regard as an artifact or degradation product. However, the absence of the wine pigment in extracts from red animals strongly suggests that it is a natural pigment.

\section{Genotypes}

Two breeding programmes clarified the genetics of red. Each was dictated by the fact that females store sperm. In one, gravid females were 
collected from natural populations and the segregation ratios of their broods determined. Since these young have not mated successfully, another programme using wild-caught virgins was begun. In both cases, separate stocks were taken from the Searls population (site A in fig. 3, frequency of red $=0.20$ ) and the Murray population (site A in fig. 3, frequency of red $=0 \cdot 36$ ). The young were scored for colour at the age of 3 months and for sex at 7 months. Tables 1 and 2 give the results. Clearly, red behaves as a recessive trait.

\section{FRONT}

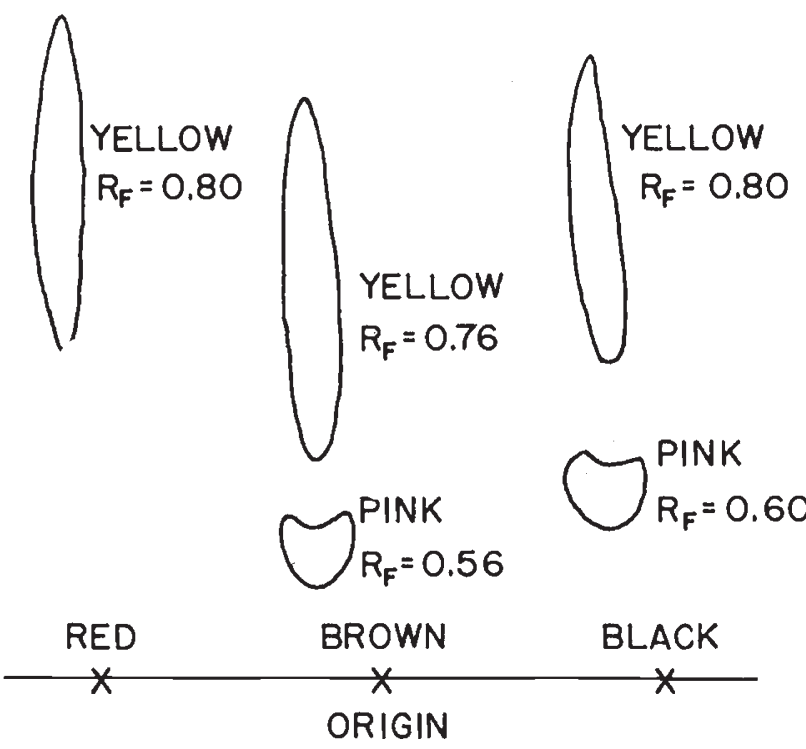

FIG. 2.- Tracing of an ascending chromatogram of the extracted pigments; the difference in $R_{f}$ values between brown and black is within the range of variability for a single extract.

The success of the matings shown in table 1 depended on the virginity of the females. To insure this, the stocks were collected in May before the breeding season had begun. Only females between 7 and $8 \mathrm{~mm}$. long were used. A study of population dynamics (Adamkewicz, in preparation) shows that larger females may be in their second breeding season while smaller ones are not sexually mature. Moreover, some of the females were isolated from males, and these did not produce young. This control excludes the possibility of parthenogenesis or prior mating. The results also confirm that the females must have been virgin when collected. Whatever the dominance, the probability that eight red females that had mated in nature would all produce non-segregating broods is vanishingly small.

The matings of intermediate females with dark males (table l) give some information on the status of brown and black. The males DS1, DS2, and DS3 were all definitely black, yet they must have been heterozygous for red. The females were all light brown, yet the results suggest that female IW2 was homozygous dark. Although brown may be a separate genotype, it clearly is not the heterozygote of red and black. 


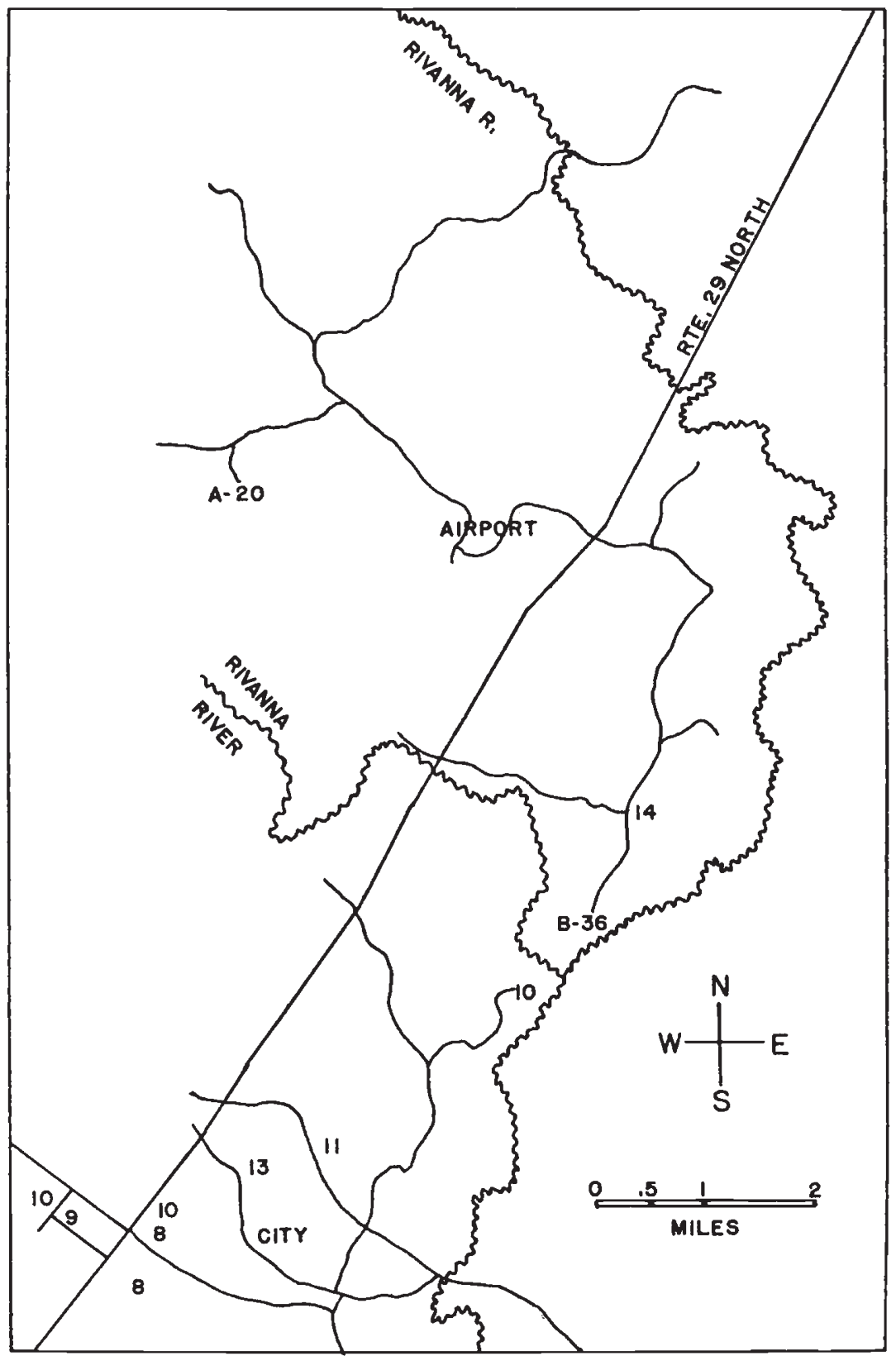

Fig. 3.-Map of the study area showing the percentage of red for 1964-66 at those sites where at least 100 isopods were collected.

Of the broods in table 2, only three are incompatible with the hypothesis that red is recessive. Two of these, red females whose broods segregated 3 dark : 1 red, were probably dark females misclassified as red. The third was a red female whose brood segregated 21 red : 6 dark. This animal came from the Murray population, and red Murray females as a whole had 


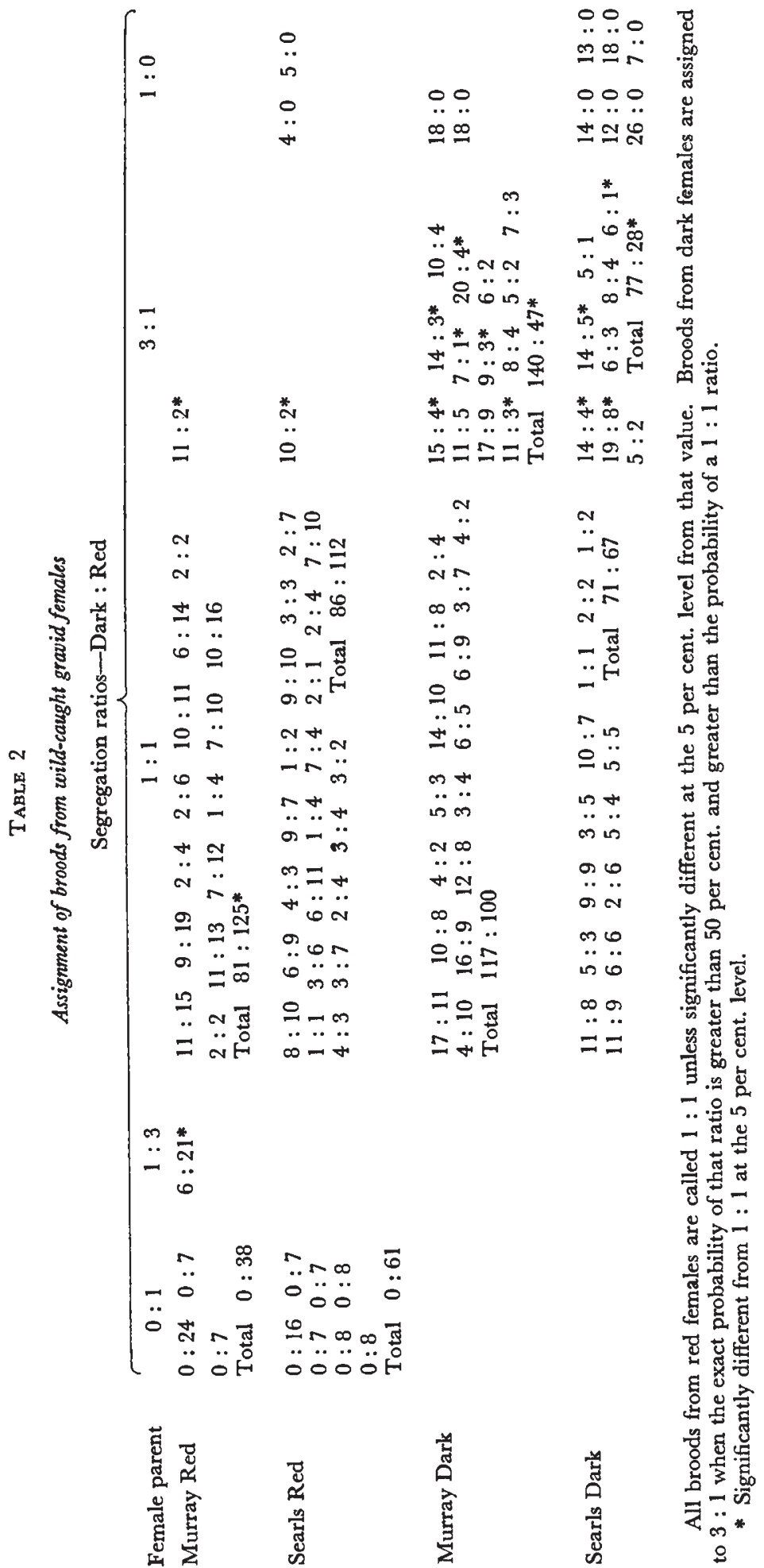




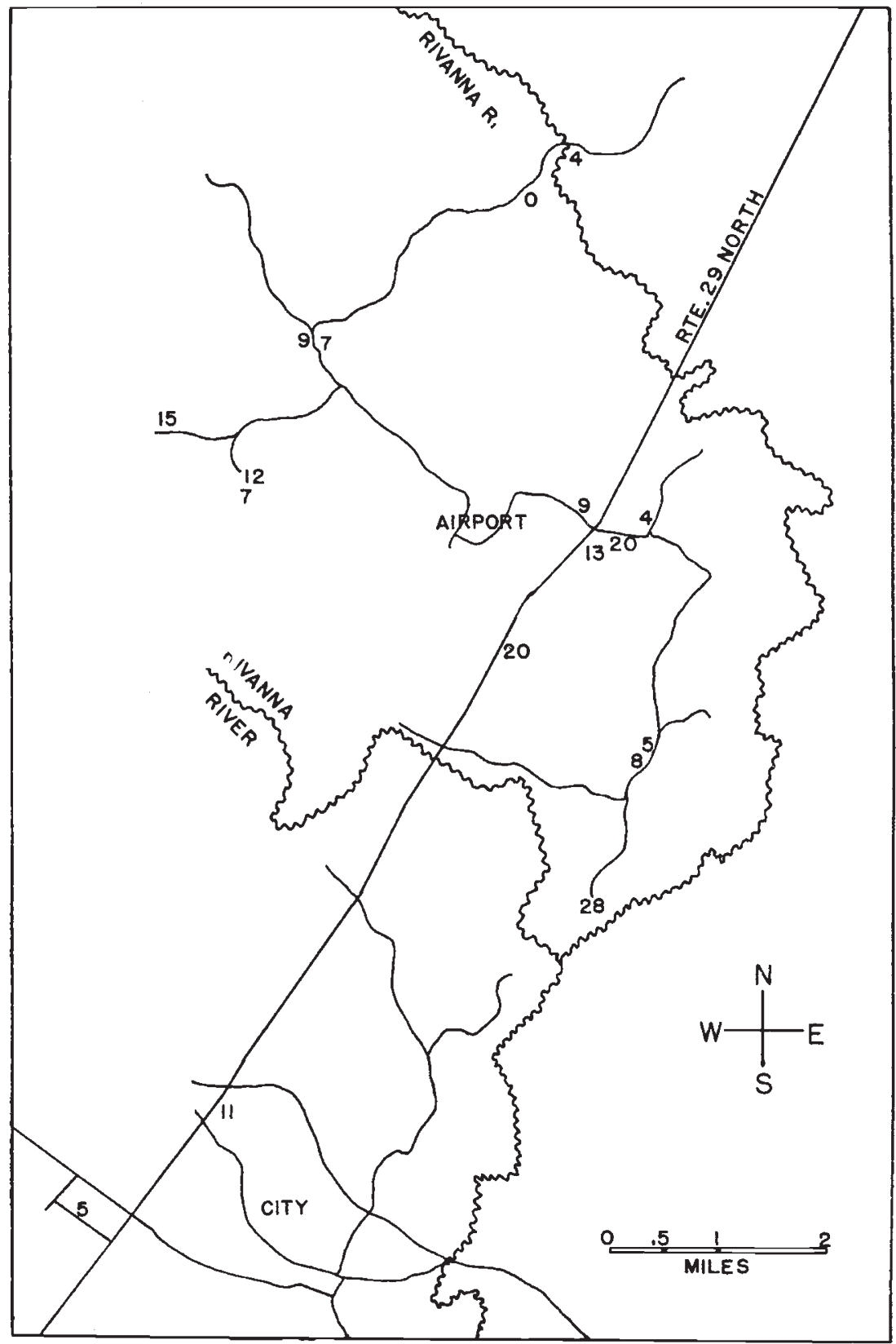

Fig. 4.-Map of the study area showing the percentage of red for 1967 at those sites where at least 100 isopods were collected.

a significant excess of red offspring. If differential viability or low penetrance were the cause, one would expect to see the effect in all four classes of females, but one does not. An alternative explanation is that a dominant red exists in the population at low frequency. If so, the excess red progeny would appear primarily in the broods from red females and some 
3 red : 1 dark ratios would occur. Unfortunately, none of the young from Murray females has mated. Until more genetic evidence is available, one can only say that the hypothesis is plausible. In any case, the problem does not detract from the very clear evidence that in these populations red is usually recessive to dark.

\section{Frequency in Natural populations}

During this study, 115 samples were collected at 38 sites. The most common frequency of red is about 10 per cent. with a range from 0 to 36 per cent. Since the variation in frequency shows no geographical pattern (figs. 3 and 4), the proportion of red must be site specific. Indeed, the frequency of red changes over a distance of only 20 metres at the Searls site (fig. 5). Overall, the 1967 samples from this site are homogeneous $\left(\chi_{(26)}^{2}=35 \cdot 32, \mathrm{P}>0 \cdot 1\right)$. However, the barn shows consistently lower frequencies, and a partition of the $\chi^{2}$ shows that the difference between the barn and the remaining areas is highly significant $\left(x_{(1)}^{2}=13.41, \mathrm{P}<0.001\right)$. As the maps indicate, equally striking changes occur over distances of about one mile. When such abrupt shifts occur over short distances, one cannot expect to see a county-wide pattern or cline.

Several variables were recorded for each site: the nature of the cover, the type of vegetation, the amount of shade, the presence of other species of isopods, the nature of the soil, and the rate of drainage. No correlation was found between the frequency of red and any of these factors (Adamkewicz, unpublished). In addition, the colour forms were tested for fecundity, adult viability in the laboratory, and resistance to desiccation. No significant differences were found. The one monomorphic population occurred at a site that appeared in no way unusual. At the Searls site, the pen and barn were ecologically very similar while differing in the frequency of red. The pen and house differed in aspect, the nature of the cover, and vegetation; but they had the same frequency of red.

Nevertheless, two lines of evidence show that natural selection must be operating on the system. The first of these is the change of frequency with time. In Virginia, A. nasatum produces two broods per year between June and late August, and the population replaces itself every two or three years. The population size is over 6000 at the Searls pen site and probably that large at the Murray site. At the Murray site, the frequency of red was stable from September of 1964 to Ocotber of 1966, a span of at least four generations. The two other sites that were followed for over a year, Searls and Lewis Mountain, also had stable frequencies at all seasons. Sometime between October of 1966 and February of 1967 the frequency of red at the three sites dropped markedly and significantly (table 3 ). The low frequencies persisted throughout 1967, but by the spring of 1968 they had risen toward their former levels.

The study itself probably did not cause this decline. Collecting pressure was heavy throughout the year at the Searls and Murray sites; but the Lewis Mountain site was sampled only twice in 1966, both times well before the breeding season and twelve months before the 1967 collections. Furthermore, the Murray population had been sampled for three previous years without a change. Subjective changes in scoring procedures are not likely in view of this earlier consistency. These considerations suggest 
that the study did not influence the polymorphism. Since the 1967 decrease took place during a period with no births, it must have been caused by a
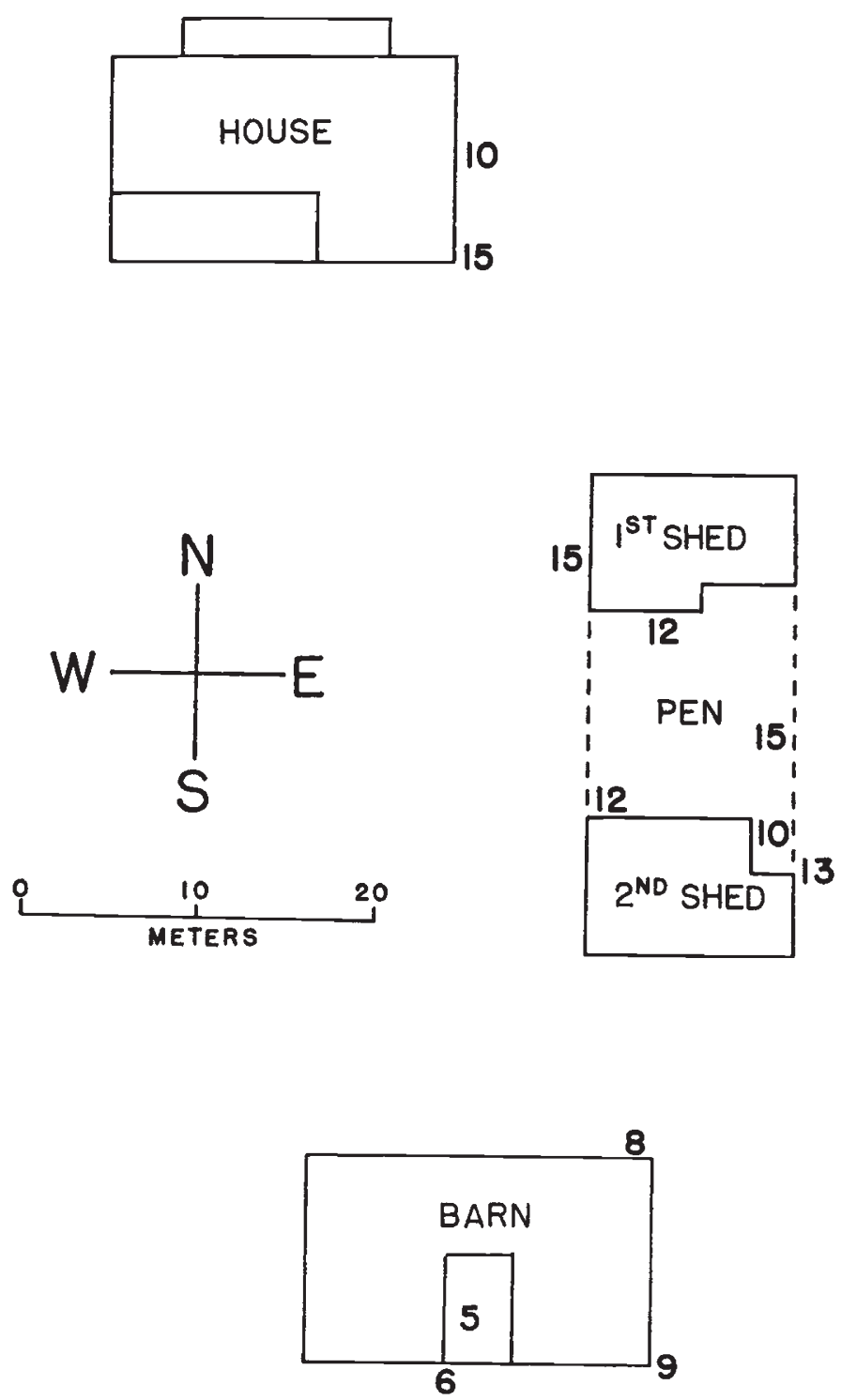

Fig. 5.-Map of the Searls site, not to scale, showing the frequency of red and the location for some samples from 1967.

change in the relative death rates. Stability over several years followed by a rapid decline and a return toward normal certainly suggest that the polymorphism is a balanced one.

The second line of evidence shows that differential viability exists among the young. In table 4, the frequency of red is consistently, but not significantly, lower among males than among females. In 88 samples from 


\section{TABLE 3}

Analysis of the sampling data for the change of frequency over time

IA. Collections from the Searls site

$\begin{array}{lccc}\text { Site and date } & \begin{array}{c}\text { Number of } \\ \text { samples }\end{array} & \text { Red +Dark }=\text { Total } & \text { Frequency of red } \\ \text { House } & 5 & 271+1071=1342 & 0 \cdot 2019 \\ \text { Pen } & 8 & 297+1170=1467 & 0 \cdot 2024 \\ \text { House } & 5 & 180+1260=1440 & 0 \cdot 1250 \\ \text { Pen } & 16 & 441+3242=3683 & 0 \cdot 1197 \\ \text { Barn } & 6 & 84+940=1024 & 0.0820\end{array}$

Iв. Homogeneity $\chi^{2}$ for Searls

$\begin{array}{lccc}\text { Class } & \begin{array}{c}\text { Degrees of } \\ \text { freedom }\end{array} & \chi^{2} & \text { Probability } \\ 1967 & 26 & 29 \cdot 3959 & \text { n.s. } \\ 1966 & 12 & 11.4930 & \text { n.s. } \\ \text { Between } & 1 & 120.9875 & \text { less than } 0.001 \\ \text { Total } & 39 & 161.8764 & \text { less than } 0.001\end{array}$

IIA. Collections from the Murray site

$\begin{array}{cccc}\text { Date } & \begin{array}{c}\text { Number of } \\ \text { samples }\end{array} & \text { Red +Dark }=\text { Total } & \text { Frequency of Red } \\ 1964 & 2 & 154+311=465 & 0 \cdot 3311 \\ 1965 & 4 & 240+411=651 & 0 \cdot 3686 \\ 1966 & 8 & 545+980=1525 & 0 \cdot 3573 \\ 1967 & 6 & 369+945=1314 & 0 \cdot 2808\end{array}$

IIB. Homogeneity $\chi^{2}$ for Murray

$\begin{array}{lccc}\text { Class } & \begin{array}{c}\text { Degrees of } \\ \text { freedom }\end{array} & \chi^{2} & \text { Probability } \\ 1964 & 1 & 5 \cdot 8294 & \text { less than } 0 \cdot 05^{*} \\ 1965 & 3 & 7 \cdot 2416 & \text { n.s. } \\ 1966 & 7 & 8 \cdot 5681 & \text { n.s. } \\ 1967 & 5 & 4 \cdot 1383 & \text { n.s. } \\ \text { Among } & 3 & 23 \cdot 6810 & \text { less than } 0 \cdot 001 \\ \text { Total } & 19 & 49 \cdot 4584 & \text { less than } 0 \cdot 001\end{array}$

IIIA. Collections from the Lewis Mountain site

\section{Date}

October 1965

March 1966

April 1966

March 1967

$$
\begin{array}{rlrl}
\text { Red Dark } & =\text { Total } & \text { Frequency of Red } \\
16+185 & =201 & 0.0796 \\
7+58 & =65 & 0.1076 \\
14+100=114 & 0.1228 \\
31+533=564 & 0.0549
\end{array}
$$

IIIв. Homogeneity $\chi^{2}$ for Lewis Mountain

$\begin{array}{lccc}\text { Class } & \begin{array}{c}\text { Degrees of } \\ \text { freedom }\end{array} & \chi^{2} & \text { Probability } \\ 1965-1966 & 2 & 2 \cdot 1461 & \text { n.s. } \\ 1967 & 0 & - & \text { less than } 0.01 \\ \text { Between } & 1 & 6 \cdot 0762 & \text { less than } 0.05\end{array}$

* Involves a sample from an outlying area that was not available in later years. 
17 sites, the frequency of red was higher in males than females in only 19 samples (for the deviation from $1: 1, \chi_{(1)}^{2}=28, \mathrm{P}<0.001$ ). The observed sex ratio varies widely, but the frequency of red is lower among males no matter which sex is deficient. The evidence indicates that the variable sex ratio is caused by differential behaviour of the two sexes and that the underlying ratio is $1: 1$ (Adamkewicz, 1968). However, the variation prevents one from using the sampling data to determine which class is deficient, red males or dark females. Fortunately, the laboratory data show the same effect. At 7 months of age, the progeny of the wildcaught gravid females were 137 red males, 144 red females, 191 dark males and 144 dark females. Although the sex ratio overall and among reds is $1: 1$, it is not so among dark offspring $\left(\chi_{(1)}^{2}=6 \cdot 6, \mathrm{P}<0.01\right)$. The deficiency is clearly in dark females.

\section{Discussion}

The variation of body colour in $A$. nasatum is clearly a genetic polymorphism with a recessive gene resulting in the absence of a dark pigment and the unmasking of a light pigment that is always present. Preliminary work shows that black individuals of $A$. vulgare have the same two pigments. Although red animals of that species were not available, one can speculate that all recessive red phenotypes in the Oniscoidea have a similar basis. The nature of dominant red is unknown. The red morph of $A$. nasatum is dominant in France (Vandel, 1945), and a rare dominant may exist in Virginia. A. vulgare has both reds in a single population, and they are controlled by alleles, with dominant red the commoner of the two (Howard, 1953, 1962). Although $A$. vulgare occurs in Albemarle County, the red form has not been observed there.

The evidence does indicate that selection maintains the polymorphism. Only selection accounts satisfactorily for a polymorphism that exists in many populations at different, stable frequencies. Aside from one monomorphic population, the lowest observed frequency of red was 0.04 , suggesting that random loss does not occur. Moreover, the change in frequency in 1967 and the consistently lower proportion in males both indicate differential mortality of the colour forms.

What the agent of selection may be is not clear, but winter weather was probably involved in the 1967 decline. The change coincided with unusually warm January temperatures, the highest in 11 years. The weather during January of 1968 was normal, and by April of 1968 the frequency of red had risen to a level intermediate between the 1966 and 1967 values. This observation strongly suggests that winter weather caused the original decline either directly through temperature effects or indirectly, perhaps by influencing the humidity.

The difference in phenotypic frequencies between the two sexes is rather unusual. Although the difference is not significant in any one sample, it is noticeable in nearly all. Either differential viability or sex influence on colour might account for this observation. If heterozygous females, but not males, were sometimes red, it would account for the inequality. However, red females should then be in excess among the progeny, and they are not. Furthermore, red males are scored " uncertain red" as often as females are. The more probable explanation is that dark females are less viable than dark males and that in natural populations this leads to a higher frequency 


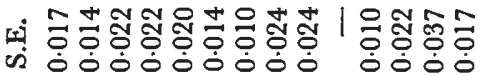

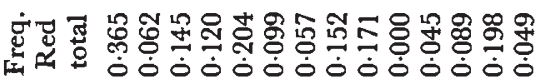

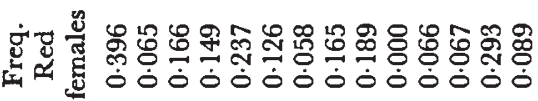
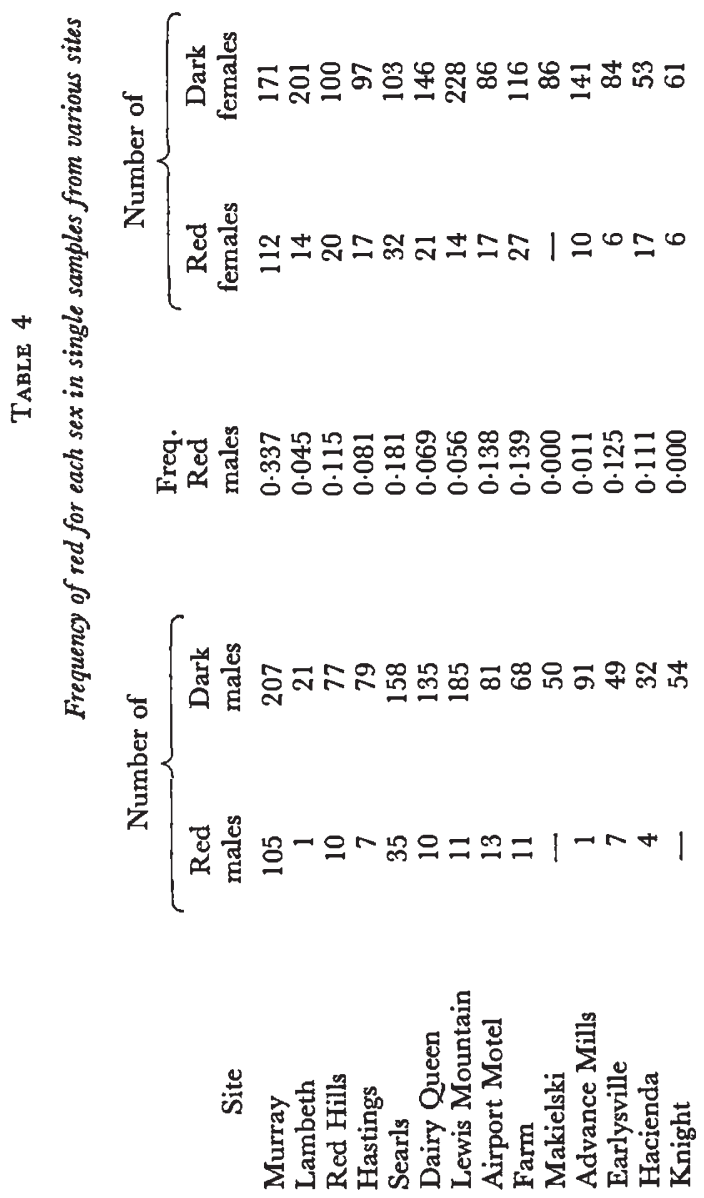

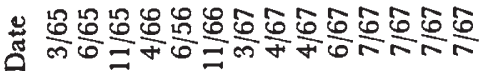


of red among females. Since the frequency of red in males is the same among first- and second-year animals, the deficiency must be established before the secondary sex characters develop. Most young reach sexual maturity in April or May at the age of about 8 months, suggesting that differential mortality, like the unusual change in 1967, occurs during the winter months.

The results in tables 1 and 2 indicate that homozygous dark animals of both sexes are deficient in natural populations. The frequency of nonsegregating dark broods from red females should equal the frequency of homozygous dark males in the population, yet only two such broods appear in table 2. Non-segregating broods from dark females are also deficient in both tables. Even the presence of a rare dominant red cannot account for this latter deficiency.

The evidence does favour a real deficiency of dark females as the cause of different phenotypic frequencies in the two sexes. Instances of sex-limited polymorphisms are common in mimetic butterflies (Ford, 1964), and the polymorphism for pattern in $A$. vulgare is sex limited to females (Howard, 1962). However, cases are very rare in which the sexes differ in phenotypic frequencies in the absence of sex linkage or sex limitation. Spotting in the butterfly Maniola jurtina may be an example (Dowdeswell, 1961), but sex influence on the phenotype is an equally likely interpretation of this case. In contrast to its rarity in other groups, the phenomenon may be common in oniscoid isopods. Although he does not comment on it, Howard's collections $(1940,1962)$ show that the frequency of red is lower in males than females of $A$. vulgare, and de Lattin $(1951,1954)$ has shown the same for marbled body colour in Porcellio scaber. The genes in $A$. vulgare and $P$. scaber are dominant; in $A$. nasatum, recessive. However, a single locus controls each character, and none is sex limited.

One model of selection can account for all three polymorphisms. If selection acts primarily or entirely against one homozygote in one sex and the other homozygote in the other sex, the result is a special case of heterozygous advantage. One result is the deficiency of one phenotype in each sex. The existence of a truly sex-limited polymorphism in A. vulgare is evidence that the selective advantages of colour and pattern can differ in the two sexes of isopods.

$A$. nasatum and $P$. scaber show deficiencies in the laboratory as well as in natural populations. Cultures of $P$. scaber breeding true for marbled contained about 32 per cent. males while cultures of solid coloured animals were about 69 per cent. male. In the combined brood data for $A$. nasatum, red progeny were 49 per cent. male, and darks were 57 per cent. male. De Lattin prefers the hypothesis that the pattern locus influences sex determination, but he notes that differential viability might also explain the data. In natural populations of $P$. scaber, the frequency of males among marbled increases with increasing overall frequency of marbled (de Lattin, 1951, 1954). If colour affects sex determination, the observation requires an intricate explanation, while it is exactly what one expects if different viabilities in the sexes maintain the polymorphism.

\section{Summary}

1. A. nasatum in Albemarle County, Virginia, possesses three colour forms, red, black, and brown. At least two, red and black, are genetically 
distinct. A recessive gene controls red, but some evidence suggests that a dominant gene for red is also present.

2. The body colours are due to ommochrome pigments in the epidermis. Dark isopods have two pigments only one of which is present in red animals.

3. The frequency of red in natural populations varies over both space and time. The typical value in Albemarle County is about 10 per cent. with extremes of 0 and 36 per cent. The shortest distance over which a change in frequency was detected was approximately 20 metres; the shortest time, four months.

4. The frequency of red declined markedly in widely separated populations during the winter of 1966-67 and rose again in the spring of 1968 . The probable cause was unusually warm weather in January of 1967.

5. No correlation was found between the frequency of red and any environmental variable.

6. In samples from natural populations the frequency of red is lower among males than among females. Dark females are deficient in laboratory raised broods, accounting for the lower frequency in males. This difference is established before sexual maturity. Homozygous dark adults of both sexes may be deficient. Selection primarily against both dark females and red males could provide conditions sufficient to maintain a balanced polymorphism.

Acknowledgments.-The author gratefully acknowledges the help of Dr J. J. Murray, Jr., who first drew her attention to the polymorphism and whose constant guidance and advice made the study possible. I thank the many people who permitted the use of their land for their kindness and co-operation. I also thank Professor Dietrich Bodenstein for providing the facilities for this study.

\section{REFERENCES}

BRERETON, J. LE G. 1957. The distribution of woodland isopods. Oikos, 8, 85-106.

CAIN, A. J., AND SHEPPARD, P. M. 1954. Natural selection in Cepaea. Genetics, 39, 89-116. DowDESWELL, W. H. 1961. Experimental studies on natural selection in the butterfly, Maniola jurtina. Heredity, 16, 39-52.

EDNEY, E. B. 1954. Woodlice and the land habitat. Biol. Rev., 29, 185-219.

FISHER, R. A., AND FORD, E. B. 1947. The spread of a gene in natural conditions in a colony of the moth Panaxia dominula L. Heredity, 1, 143-174.

FORD, E. B. 1964. Ecological Genetics. John Wiley and Sons Inc., New York.

HATCHETT, s. P. 1947. Biology of the Isopoda of Michigan. Ecol. Monogr., 17, 47-79.

HOWARD, H. W. 1940. The genetics of Armadillidium vulgare Latr. I. A general survey of the problems. F. Genet., 40, 83-108.

HowARD, H. W. 1953. Genetics of Armadillidium vulgare Latr. III. Dominant and recessive genes for red body color. F. Genet., 51, 259-269.

HowARD, H. W. 1962. Genetics of Armadillidium vulgare Latr. V. Factors for body color. F. Genet., 58, 29-38.

LATTIN, G. DE. 1939. Untersuchungen über die Farbvariabilität der Isopoden. I. Úber genotypishe und modifikative Pigmentreduktion. Zool. Anz., 125, 309-324.

LATTIN, G. DE. 1951. Untersuchingen über die geschlechtsbeeinflussende Wirkung von arbfaktoren bei Porcellio und Tracheoniscus. Z. Vererbungsl., 84, 1-37.

LATTIN, G. DE. 1954. Zur Populationsgenetik geschlechtsbeeinflussender Farbfaktoren bei Porcellioniden (Crust. Isop.). Caryologia, 6 (suppl.), 883-888.

LEE, W. L. 1966. Pigmentation of the marine isopod Idothea montereyensis. Comp. Biochem. and Physiol., 18, 17-36.

NEEDHAM, A. E., AND BRUNET, P. c. J. 1957. The integumental pigment of Asellus. Experientia, 13, 207-209.

PARIS, O. H. 1963. The ecology of Armadillidium vulgare in California grassland. Food, enemies, and weather. Ecol. Monogr., 33, 1-22. 
PARIS, O. H., AND PITElKA, F. A. 1962. Population characteristics of the terrestrial isopod Armadillidium vulgare in California grassland. Ecology, 43, 229-248.

schultz, G. A. 1961. Distribution and establishment of a land isopod in North America. Syst. Zool., 10, 193-196.

VANDEL, A, 1945. Recherches de genetique sur quelques Oniscoides. Bull. Biol. France et Belgique, 74, 168-216.

VANDel, A. 1960. Isopodes terrestres (Primier Partie). Faune de France, 64, 1-416.

VANDEl, A. 1962. Isopodes terrestres (Deuxieme Partie). Faune de France, 66, 417-931.

WARBURG, M. R. 1965. The evolutionary significance of the ecological niche. Oikos, 16, 205-213. 